\title{
Capillary Hemangioma of the Hard Palate: A Rare Childhood Tumor
}

\author{
Rilna $P^{1 *}$, Sankar $K^{2}$, Sathyanarayanan $\mathbf{R}^{1}$, Tamizhp Pozhil Guna ${ }^{1}$, Nithin Joseph Jude ${ }^{1}$ and Raghu $\mathrm{K}^{1}$ \\ ${ }^{1}$ Department of Oral and Maxillofacial Surgery, Indira Gandhi institute of dental sciences, Puducherry, India \\ ${ }^{2}$ Department of Oral and Maxillofacial Surgery, Mahathma Gandhi institute of dental sciences, Puducherry, India
}

${ }^{*}$ Correspondence author: Rilna P, Indira Gandhi Institute of Dental Sciences, Sri Balaji Vidyapeeth (SBV)-deemed to be university, SBV campus, Pillaiyarkuppam, Puducherry-607402, India; E-mail: rilnaajith@gmail.com

Received: September 05, 2019; Accepted: September 11, 2019; Published: December 10, 2019;

\begin{abstract}
Hemangioma are benign tumor of childhood occurs due to proliferation of endothelial cells of blood vessels. Although hemangioma of the head and neck region are common, these tumors are rarely seen in the oral cavity especially hard palate. Normally, such rare cases of hemangiomas can be misdiagnosed as any other pathologies. So the proper diagnosis and management is very important to reduce the intraoperative and postoperative complications. This case report presents a case of a 7 years old male who was reported in the department of Oral and Maxillofacial Surgery with the chief complaints of swelling in the left maxilla since 4 months. After excisional biopsy and histopathological study, the lesion was finally diagnosed as capillary hemangioma of the palate.No recurrence was noted at 6 months follow-up.
\end{abstract}

Keywords: Hemangioma, intraoperative complication, excision

\section{Introduction}

Hemangiomas are benign tumor of vascular endothelial origin which are painless, slow progressive in growth and can involve superficial and deep blood vessels. They are mostly seen during early childhood occurring in about $5-10 \%$ of children $<1$ year of age, which involutes over time [1]. Hemangiomas are common in the head and neck region but rare in the oral cavity ${ }^{2}$. The lesions in the oral cavity generally appear on the lips, buccal mucosa and tongue, but rarely on hard and soft palate [2,3]. Incidence of hemangiomas are more in female than males. These proliferative tumors can be seen as a single lesion in $80 \%$ of the time but $20 \%$ it can be seen as multiple lesions. The proliferation of endothelial cells does not usually undergo malignant transformation. They appear as pale macules which can be lobulated sessile or pedunculated with variable size. They may have smooth or irregular boarders. As the lesion can be confused with other common lesions in oral cavity like pyogenic granuloma, histopathological examination is very important for the final diagnosis. The variants of hemangiomas are capillary, cavernous or central depending on the vasculization system. Following case report represent an unusual location of capillary hemangioma on the hard palate of a 7 years old male patient who reported to the department of oral and maxillofacial surgery. Following the surgical excision, lesion was sent for histopathological diagnosis and confirmed as capillary hemangioma. Regular follow up of the patient was done.

\section{Case History}

A male patient aged 7 years reported to the department of oral and maxillofacial surgery with a progressively enlarging painless swelling in upper left posterior teeth region for the past 4 months. The swelling was insidious in onset, gradually progressive and there was no history of any pain, discharge or bleeding. Extra orally no abnormalities detected (Figure 1). Intraoral examination revealed a solitary broad based pinkish growth of size $1.5 \times 1.5 \mathrm{~cm}$, present on the left posterolateral part of the hard palate just $0.5 \mathrm{~cm}$ lateral to the midline on the left side in relation to the deciduous left maxillary first and second molars. Swelling has a well-defined border, which was not interfering the occlusion (Figure 2). On palpation swelling was non-tender and firm in consistency. Panoramic radiograph did not reveal any pathological changes in relation to 64 and 65 (Figure 3). A provisional diagnosis of hemangioma was made based on clinical and radiographic findings. The lesion was excised under general anesthesia and tooth no. 64 and 65 were extracted (Figure 4). Wound was sutured. . Following that, the tissue specimen was sent for histopathological study, which shows lobulated cellular growth which containing proliferating endothelial cells, combination of numerous well and poorly canalized blood vessels which are lined by endothelial cells. The epithelium is parakeratotic stratified squamous type. The intervening connective tissue stroma is fibrillar composed of loose bundles of collagen fibers. It is sparsely infiltrated with chronic inflammatory cells predominantly lymphocytes and plasma cells. On the basis of clinical and histopathological findings lesion was finally diagnosed as capillary hemangioma of the hard palate. Satisfactory uneventful wound healing occurred after 1 month .Nance palatal arch space maintainer was delivered to the patient .No recurrence of the lesion was noted after 6 months of follow-up. 


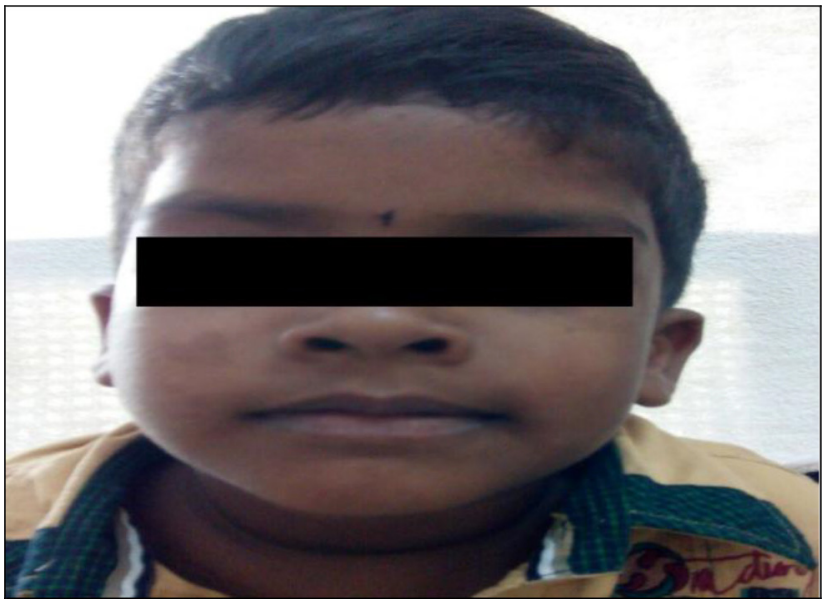

Figure 1.

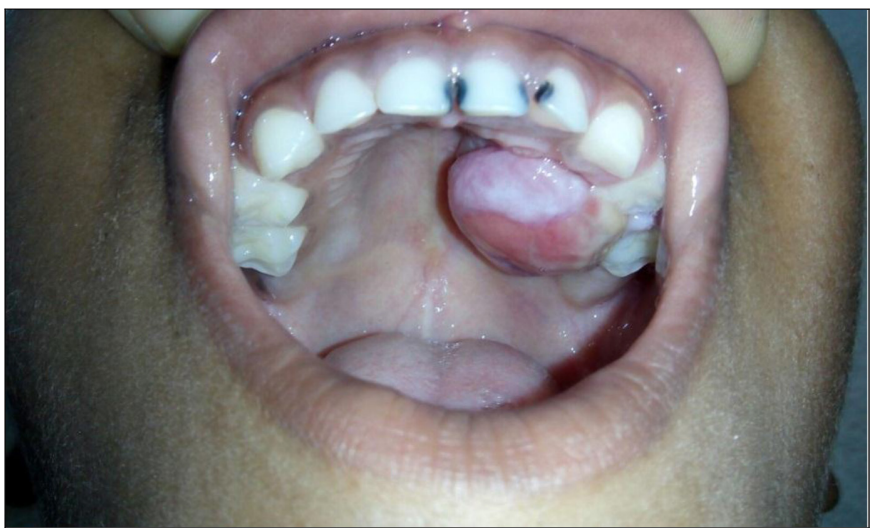

Figure 2.

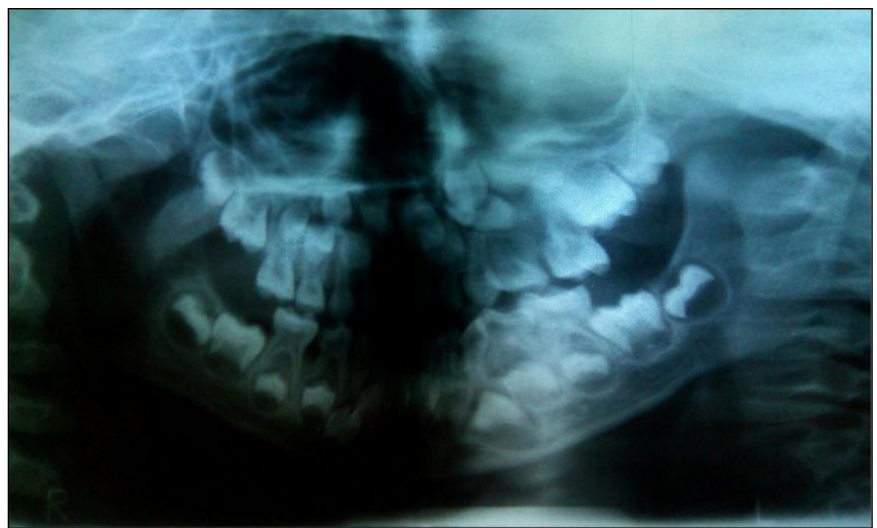

Figure 3.

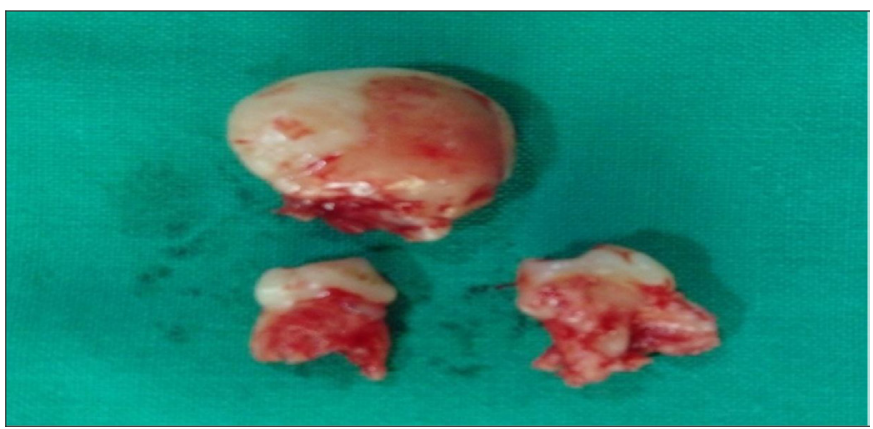

Figure 4.

\section{Discussion}

Vascular lesions can be generally divided into hemangiomas and vascular malformations. In 1982, Mullikan and Glowacki described the classification based on clinical and microscopic features [4]. Hemangiomas are considered as true neoplasm of the vascular endothelial cells, but some controversy still occurs whether to classify hemangiomas as malformation or hamartomas [5]. Lesions commonly occurs as small or large superficial growth and can be unicentric or multicentric. Normally capillary hemangiomas are seen as superficial small pedunculated lesions which differ from other variants like central and cavernous which occurs as large superficial or deep lesions [1]. Also capillary hemangiomas can be seen as sessile or pedunculated lesions which are painless unless traumatized. In the present case, lesion was superficial and pedunculated which suggestive of capillary variant. Since there are no particular criteria for the diagnosis of capillary hemangiomas, proper clinical history and histopathological study can help to diagnose the lesion. In the present case, history of occurrence of lesion within few months with slow progressive in growth and clinical examination helps to suggest the lesion as capillary hemangioma. Ocurrence of hemangiomas is very rare especially in the hard palate and very few cases were reported in literature of occurrence in the oral cavity. Usually hemangiomas do not affect the adjacent bone which supports the present study which does not shows any involvement of adjacent bone. Pyogenic Granuloma $(\mathrm{PG})$, peripheral giant cell granuloma, epulis granulomatosa, and squamous cell carcinoma should be included in the differential diagnosis of hemangiomas [6,7]. Management is based on age of the patient, size extend and variant of hemangiomas in the oral cavity [8]. Normally no intervention is required in early stages since there is a chance of involution of the lesion on aging. But in the present case, since the lesion was small without any bony involvement and to finalize the diagnosis, excisional biopsy was planned. Small lesions can successfully excised without any complications and with the support of proper bleeding control $[9,10]$.

In the present case, since the hemangioma was small and superficial, excision of the lesion was done as the management. Most common complication which can occurs can be intraoperative bleeding, which has to be controlled with proper measures to minimize the blood loss. In the present case bleeding was controlled using local pressure application and cauterization. And the wound healing was uneventful. Recently reported treatment modalities for hemangiomas in the literature includes steroid therapy, electrosurgery, Nd:YAG laser, CO2 laser, cryosurgery, and sclerotherapy [11,12]. Nowadays, sclerotherapy is used largely because of its ability and efficiency to preserve the surrounding tissue [13].

In our patient, since the tumor was causing difficulty in swallowing and was impairing speech, surgical excision was carried out. Some studies have reported the recurrence of hemangioma after surgical management $[14,15]$. The case described here demonstrates that there has been no subsequent hemorrhage or other evidence of recurrence.

\section{Conclusion}

Dental practitioners and oral surgeons need to be aware with such unusual presentations of hemangioma in the oral cavity, so that 
they are treated appropriately without any serious intraoperative and postoperative bleeding risks.

\section{References}

1. Neville BW, Damm DD, Allen CM et al. (2009) Oral and maxillofacial pathology. (3rdedn), St Louis: Saunders 2008.

2. Dilsiz A, Aydin T, Gursan N (2009) Capillary hemangioma as a rare benign tumor of the oral cavity: a case report. Cases $J$ 2: 8622 .

3. Yoon RK, Chussid S, Sinnarajah N (2007) Characteristics of a pediatric patient with a capillary hemangioma of the palatal mucosa: a case report. Pediatr Dent 29: 239-42.

4. Mulliken JB, Glowaki J (1982) Hemangioma and vascular malformation in infants and children: classification based on endothelial characterstics. Plast Reconstruct Surg 69: 412-20.

5. Barnes L (1985) Tumours and tumour-like lesions of the soft tissues. In: Barnes L (ed.), Surgical pathology of the head and neck. New York, NY: Marcel Dekker Pg No: $725-880$

6. Singh P, Parihar AS, Siddique SN, et al. (2016) Capillary hemangioma on the palate: a diagnostic conundrum. BMJ Case Rep 2016.

7. Mufeed A, Hafiz A, George A, et al. (2015) Pedunculated hemangioma of the palate. BMJ Case Rep 2015

8. Kumari VR, Vallabhan CG, Geetha S, Nair MS, Jacob TV (2015) Atypical presentation of capillary hemangioma in oral cavity- A case report. J Clin Diagn Res 9: 26-8.

9. Rachappa M, Trivedi MN (2010) Capillary haemangioma or pyogenic granuloma: a diagnostic dilemma. Contem Clin Dent 1: 119-22.

10. Van Doorne L, De Maeseneer M, Stricker C, Vanrensbergen R, Stricker M (2002) Diagnosis and treatment of vascular lesions of the lip. Br J Oral Maxillofac Surg. 40: 497-503.

11. Varma S, Gangavati R, Sundaresh KJ, et al. (2013) Lobulated capillary haemangioma: a common lesion in an uncommon site. BMJ Case Rep 2013.

12. Acikgo"z A, Sakallioglu U, Ozdamar S, et al. (2010) Rare benign tumours of oral cavity - capillary haemangioma of palatal mucosa: a case report. Int J Paediatr Dent 10: 161-165

13. Kamala KA, Ashok L, Sujatha GP (2014) Cavernous hemangioma of the tongue: A rare case report. Contemp Clin Dent 5: 95-8.

14. Kocer U, Ozdemir R, Tiftikcioglu YO, Karaaslan O (2004) Soft tissue hemangioma formation within a previously excised intraosseous hemangioma site. J Craniofac Surg 15: 82-3.

15. Sznajder N, Dominguez FV, Carraro JJ, Lis G (1973) Hemorrhagic hemangioma of gingiva: report of a case. $J$ Periodontol 44: 579-82.

Citation:

Rilna P, Sankar K, Sathyanarayanan R, Pozhil Guna T, Joseph Jude N, Raghu K (2019) Capillary Hemangioma of the Hard Palate: A Rare Childhood Tumor. J Dent Maxillofacial Res Volume 2(4): 1-3. 